\title{
Understanding the apprehension and concern haunting patients before a total knee arthroplasty
}

Sanjay Bhalchandra Londhe ${ }^{1 *}$ (D), Ravi Vinod Shah ${ }^{2}$, Meghana Patwardhan ${ }^{3}$, Amit Pankaj Doshi $^{4}$, Shubhankar Sanjay Londhe ${ }^{5}$ and Kavita Subhedar ${ }^{6}$

\begin{abstract}
Purpose: The aim of this prospective study was to understand the fear and apprehension factors that play on patient's mind before total knee arthroplasty.

Methods: This retrospective cohort study included 500 consecutive patients (375 females and 125 males) who were scheduled to undergo total knee arthroplasty the next day. The patients were asked to list the most important fear in their mind regarding the operation in descending order of importance. They were given a questionnaire form which contained several capture points, including age, gender, educational background, occupation, and provision of help at home. Preoperative pain was measured by using the visual analog score, and its influence on the patients' fear and apprehension factors was also measured.

Results: In this study, 58\% of patients (50 males, $40 \%$; 240 females, 64\%) were fearful of the pain that they would experience after surgery and during the postoperative physiotherapy. The female patients showed more fear of pain than their male counterparts $(P<0.05)$. 18\% of the patients (40 males, 32\%; 50 females, 13\%) listed whether they will be able to walk and perform activities of daily living after surgery as the most important fear. The male patients had more fear of returning to normal walking $(P<0.05)$. 20\% of the patients (30 males, 24\%; 70 females, $19 \%)$ were fearful about getting adequate home help after discharge from hospital $(P>0.05)$. $4 \%$ of patients were concerned about withstanding such a major operation. There was no difference between male and female patients $(P>0.05)$.

Conclusion: The majority of the patients experience apprehension of pain in the perioperative period of TKA. Preoperative counseling benefits pain management by alleviating the patient's concerns about the fear of postoperative pain and apprehension of returning to normal walking.
\end{abstract}

Keywords: Total knee arthroplasty, Fear and apprehension, Postoperative pain, Patient counseling

\section{Introduction}

A large population-based prevalence surveys showed that, with increased life expectancy and obesity, the incidences of the degenerative knee diseases stood at around $10 \%$ [1]. Total knee arthroplasty (TKA) is one of the most successful surgeries in modern-day orthopedics,

\footnotetext{
* Correspondence: sanlondhe@yahoo.com

${ }^{1}$ Orthopedic surgeon, Holy Spirit Hospital, Mahakali Caves Road, Andheri east, Mumbai, Maharashtra 400093, India

Full list of author information is available at the end of the article
}

and the number of surgeries performed is on the rise by the year worldwide [2].

Multiple studies have shown that the TKA could markedly improve patients' knee pain, physical function, and health-related quality of life $[1,2]$. In the developing countries, however, a sizable number of patients refuse to undergo TKA due to certain factors, including perioperative fear and apprehension of pain, other anxiety, age, gender, area of residence, education level, occupation,

(c) The Author(s). 2021 Open Access This article is licensed under a Creative Commons Attribution 4.0 International License, which permits use, sharing, adaptation, distribution and reproduction in any medium or format, as long as you give appropriate credit to the original author(s) and the source, provide a link to the Creative Commons licence, and indicate if changes were made. The images or other third party material in this article are included in the article's Creative Commons licence, unless indicated otherwise in a credit line to the material. If material is not included in the article's Creative Commons licence and your intended use is not permitted by statutory regulation or exceeds the permitted use, you will need to obtain permission directly from the copyright holder. To view a copy of this licence, visit http://creativecommons.org/licenses/by/4.0/. 
expectation, cost, etc. Moreover, in some cases, the decision may be made by patients' family. Understanding patient's decision making has potential benefits to improve preoperative counselling, patient satisfaction and financial constraints.

The aim of this prospective study was to understand the fear and apprehension factors that play on patient's mind before TKA.

\section{Materials and methods}

The institutional review boards of the participating hospitals approved the study. Informed consent was obtained from each patient.

A total of 500 consecutive patients (375 females, $75 \%$; 125 males, 25\%) were recruited for this study. Our inclusion criterion was a patient who underwent a primary TKA. We excluded the patients who underwent a revision arthroplasty because a higher pain tolerance was likely. The mean age of female patients was 73 years (range, 66 to 82 years). The mean age of male patients was 74 years (range, 70 to 85 years).

Before surgery, the patients who were planned to undergo the TKA were asked to list the foremost important fear in their mind regarding the operation in the descending order of importance. They were given a questionnaire form including several capture points like age, gender, educational background, occupation, and help they receive (Annexure 1). The severity of fear and apprehension was scored on a 1-to-3 scale (1, mild fear; 2 , moderate fear; 3 , major or severe fear). Their responses were recorded as numerical values, ranging from 4 to 12 (Table 1). An independent observer distributed the questionnaire and the patients filled out the questionnaire and handed it over to the observer. The results were interpreted by another independent observer.
Preoperative knee pain was measured by using the 10point visual analog score, and its influence on the patients' fear and apprehension was also measured. The patients who underwent unilateral and bilateral TKAs were also compared to find whether there was a difference between those patients in their fear and apprehension. The patients who scored 7 or above were given extra counseling during the perioperative period. Six months after TKA, we asked the patients again to confirm whether they experienced preoperative apprehension and fear. This investigation was done through a telephon interview by the same independent observer.

The chi-square test was employed for statistical analysis. The degree of freedom was 1 , and a $P$ value $<0.05$ was considered statistically significant.

\section{Results}

All the 500 patients willingly participated in the study. Among them, 58\% (50 males and 240 females) reported apprehension of the pain related to the TKA and physiotherapy; $18 \%$ of the patients ( 40 males and 50 females) listed whether they would be able to walk and do activities of daily living (ADL) after TKA, which was the most important fear; $20 \%$ (30 males and 70 females) were fearful of whether they would get adequate home help once they get discharged from hospital and 4\% (5 males and 15 females) concerned whether they would be able to withstand such a major operation (Figs. 1 and 2). Regarding gender, $40 \%$ of the male patients $(n=50)$ and $64 \%$ of the female patients $(n=240)$ listed fear of pain as the most important apprehension. Female patients had significantly more fear of pain than their male counterparts (chisquare $=4.4335$; degree of freedom $=1 ; P=0.0352$ ); $32 \%$ of the male patients $(n=40)$ and $13 \%$ of the female patients $(n=50)$ reported strong apprehension whether they

Table 1 Numerical score of fear/apprehension factors

\begin{tabular}{|c|c|c|c|}
\hline Fear/ Apprehension & Severity of Fear/Apprehension & Grade/Score & Score \\
\hline \multirow[t]{3}{*}{ Fear of Pain } & Mild & I & Maximum sub-score $=3$ \\
\hline & Moderate & $\|$ & \\
\hline & Severe & III & \\
\hline \multirow[t]{3}{*}{ Fear of receiving help at home } & Mild & । & Maximum sub-score $=3$ \\
\hline & Moderate & $\|$ & \\
\hline & Severe & III & \\
\hline \multirow[t]{3}{*}{ Fear of returning to activities of daily living } & Mild & । & Maximum sub-score $=3$ \\
\hline & Moderate & $\|$ & \\
\hline & Severe & III & \\
\hline \multirow[t]{3}{*}{ Fear of withstanding surgery } & Mild & । & Maximum sub-score $=3$ \\
\hline & Moderate & $\|$ & \\
\hline & Severe & III & \\
\hline
\end{tabular}




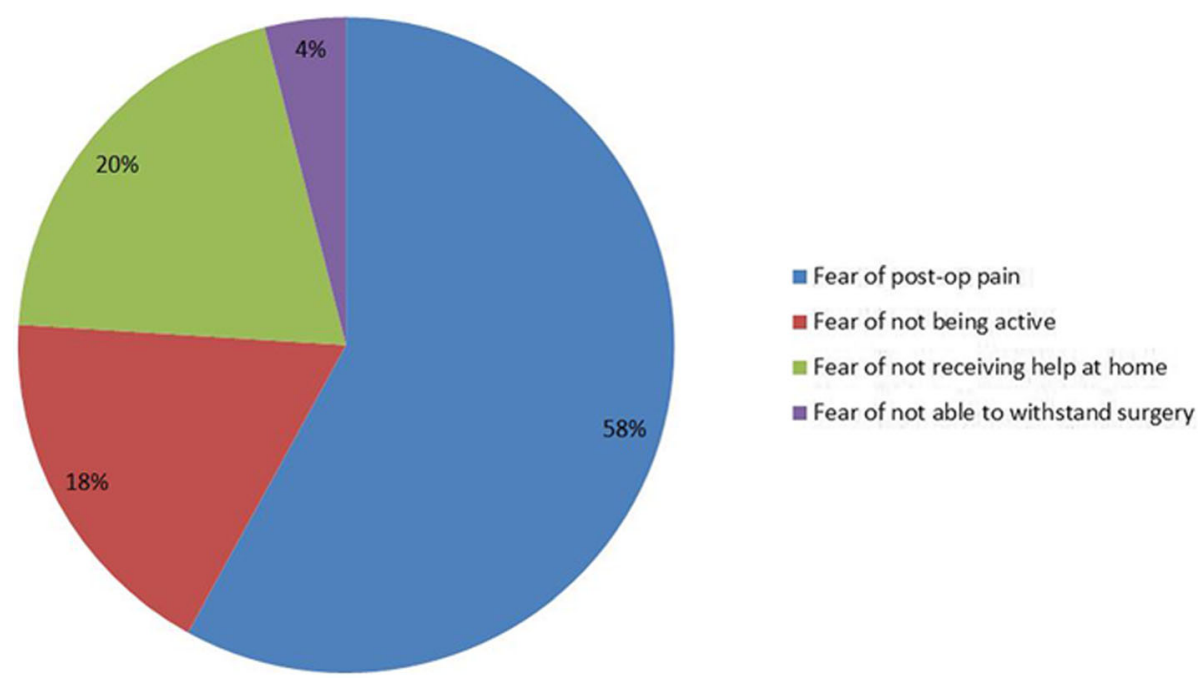

Fig. 1 Pie chart showing percentage distribution of different fear/ apprehension factors

would return to the normal walking and ADL. The male patients suffered from more fear on whether they would be able to return to the normal walking and ADL than female patients (chi-square $=4.4263$; degree of freedom $=1$; $P=0.0354) ; 24 \%$ of the male patients $(n=30)$ and $19 \%$ of the female patients $(n=70)$ primarily concerned whether they would be able to receive a domestic assistance at home after their discharge from the hospital (chi-square $=$ 0.3333 ; degree of freedom $=1 ; P=0.5637) ; 4 \%$ of both male $(n=5)$ and female $(n=15)$ patients listed the fear of withstanding the major surgery as the most important apprehension $(P=1.000)$ (Table 2). Patients whose preoperative visual analog score $>7$ reported more apprehension about returning to normal ADL than the fear of pain (Table 3). There was no statistically significant difference regarding the fear of pain, returning to normal ADL, or fear of withstanding the major surgery between patients who underwent unilateral TKAs and those receiving bilateral TKAs. Fear of not receiving help at home was more severe in the patients who underwent bilateral TKA (Table 4). Six months after TKA, the same independent observer asked the patients to report whether their preoperative apprehension and fear were unfounded. This investigation was done through a telephon interview. In this study, 95\% of the patients $(n=475)$ reported that their preoperative fear and apprehension were exaggerated; $5 \%$ of patients $(n=25)$ had genuine difficulty regarding the arrangement of help at home after discharge from hospital.

\section{Discussion}

This study highlights that apprehension and fear are important for the patients who are scheduled to undergo TKA. Majority of the patients in our cohort were concerned about the postoperative pain, and the female patients showed more fear about postoperative pain than

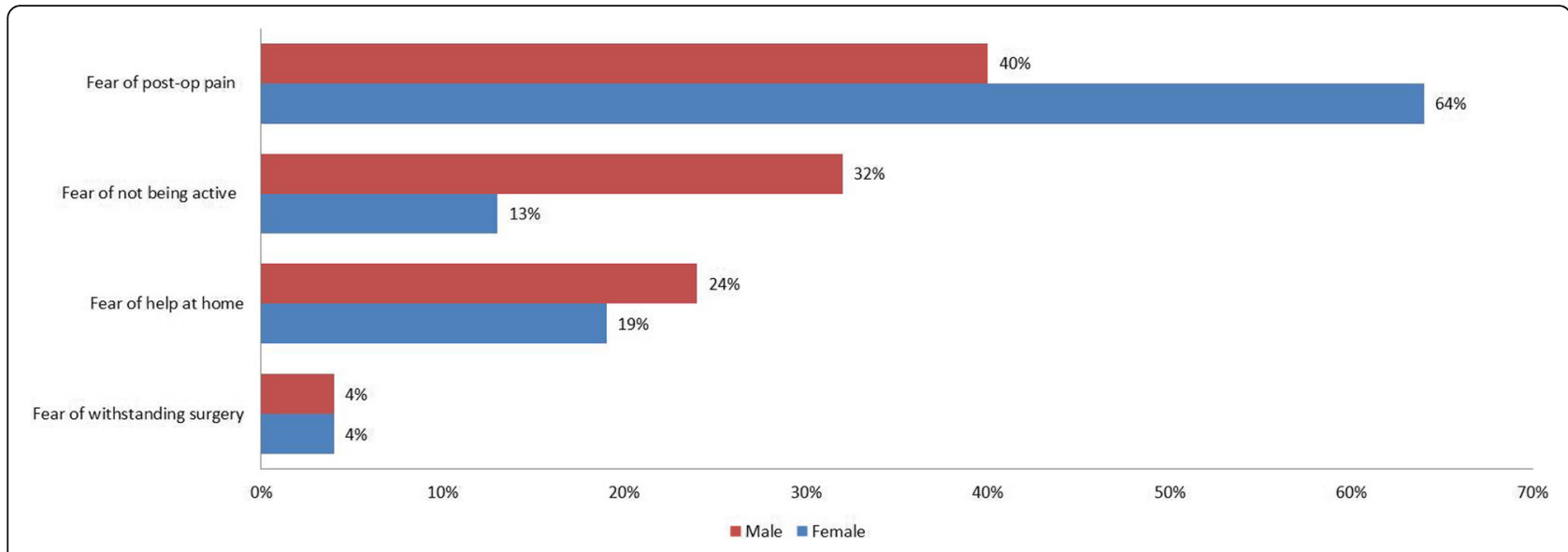

Fig. 2 Bar diagram showing distribution of fear/ apprehension factors in different gender groups 
Table 2 Gender-wise breakup of fear / apprehension factors with $p$ values

\begin{tabular}{llll}
\hline & Male & Female & $\boldsymbol{P}$ value \\
\hline Total number of patients & 125 & 375 & \\
Fear of pain & 50 & 240 & 0.03524 \\
Fear of return to normal activities / ADL & 40 & 50 & 0.03539 \\
$\begin{array}{l}\text { Apprehension about receiving domestic } \\
\text { help }\end{array}$ & 30 & 70 & 0.5637 \\
Fear of withstanding major surgery (TKA) & 5 & 15 & 1.000 \\
\hline
\end{tabular}

male patients. The male patients had more fear than female patients regarding returning to the normal walking and ADL. The female and male patients showed nearly equal fear about the help they receive at home during the postoperative period and the fear of withstanding the major surgery.

Said et al. [3] showed that the African-American patients were less likely to consider TKA than the white patients, because the former's perception of hospital course, pain, and functional recovery might be different. Vina et al. [4] found that social support affected patients' preference for TKA in the white patients rather than in the African-American patients. Liang et al. [5] demonstrated that the TKA is a cost-effective surgery for the advanced osteoarthritis of the knee joint, especially in aging populations. In developing countries, however, $65 \%$ of patients refuse to receive TKA due to the certain factors, such as the high total cost, the fear of complications, etc. [6] Zhao et al. [7] also suggested the patient factors contributed to the decision to delay TKA. The fear of pain is the number one factor in the initial postoperative weeks, and next comes the interference with work. Other factors that affect the decision-making include gender and income, and educational background does not significantly affect the decision-making. Sharifa et al. [8] conducted a systematic research of the databases like MEDLINE, PubMed, etc. They found that the preoperative anxiety is the most important predictor of poor outcomes (in terms of higher levels of knee disability and poor WOMAC score) and poor quality of life one year after surgery [9-12].

Table 3 Comparison in terms of preoperative VAS score with $P$ values

\begin{tabular}{|c|c|c|c|}
\hline & $\begin{array}{l}\text { Patient's with } \\
\text { VAS } \leq 7\end{array}$ & $\begin{array}{l}\text { Patient's with } \\
\text { VAS }>7\end{array}$ & $P$ value \\
\hline Total number of patients & 160 & 340 & \\
\hline Fear of pain & $103(64.37 \%)$ & 187 (55\%) & 0.0479 \\
\hline $\begin{array}{l}\text { Fear of return to normal } \\
\text { activities / } A D L\end{array}$ & $18(11.25 \%)$ & $72(21.17 \%)$ & 0.0071 \\
\hline $\begin{array}{l}\text { Apprehension about } \\
\text { receiving domestic help }\end{array}$ & $33(20.26 \%)$ & 67 (19.70\%) & 0.8106 \\
\hline $\begin{array}{l}\text { Fear of withstanding } \\
\text { major surgery (TKA) }\end{array}$ & $6(3.75 \%)$ & $14(4.12 \%)$ & 0.8453 \\
\hline
\end{tabular}

Table 4 Comparison between unilateral and bilateral TKA with $p$ values

\begin{tabular}{llll}
\hline & Unilateral TKA & Bilateral TKA & $P$ value \\
\hline Total number of patients & 420 & 80 & \\
$\begin{array}{l}\text { Fear of pain } \\
\begin{array}{l}\text { Fear of return to normal } \\
\text { activities / ADL }\end{array}\end{array}$ & $81(19.28 \%)$ & $9(11.25 \%)$ & 0.0869 \\
$\begin{array}{l}\text { Apprehension about } \\
\text { receiving domestic help }\end{array}$ & $77(18.33 \%)$ & $23(28.75 \%)$ & 0.0329 \\
$\begin{array}{l}\text { Fear of withstanding } \\
\text { major surgery (TKA) }\end{array}$ & $17(4.04 \%)$ & $3(3.75 \%)$ & 0.9035 \\
\hline
\end{tabular}

Postoperative pain can be alleviated by epidural analgesia, regional blocks (femoral and adductor canal blocks), neuropathic pain modulators (pregabalin), etc. Ideally, postoperative pain should be managed by a team composed of orthopaedic surgeon, anesthetist, pain consultant, and rehabilitation nurse. Hence, preoperative counseling of patients is helpful for the multimodal management of pain. The patients are shown that various perioperative strategies are available for improving their quality of life, desirably through the audio-visual demonstrations. We give the patients our contact numbers so that they can reach us to report their improvement. In order to boost self-confidence of the patients to be operated, we arrange them to have an additional preoperative interactive session with the patients who have already undergone TKA. The contact numbers are included in the patient information booklets.

Our study has limitations. Some factors, such as the cost of surgery, social network, and patients' own psychological framework, also influence the patients' decision to undergo TKA, but those factors were not included. Further studies are needed to ascertain the number of patients who refuse to undergo TKA due to the fear and apprehension, and the number of patients who have already overcome the fear and apprehension after consulting doctors about the surgical procedure and postoperative management.

\section{Conclusion}

Our study demonstrated that most of the patients experienced apprehension of pain in the perioperative period of TKA. Preoperative counseling benefits pain management by alleviating the patients' fear about postoperative pain and apprehension of returning to normal walking.

\section{Supplementary Information}

The online version contains supplementary material available at https://doi. org/10.1186/s42836-021-00069-5.

Additional file 1 


\section{Abbreviations}

TKA: Total Knee Arthroplasty; ADL: Activities of Daily Living

\section{Acknowledgements}

We acknowledge the help provided by Mr. Vishal Jagadale, a statistician.

\section{Authors' contributions}

All authors have contributed significantly to the preparation of manuscript. The author(s) read and approved the final manuscript.

\section{Funding}

No funding was obtained.

\section{Availability of data and materials Not Applicable.}

\section{Ethics approval and consent to participate}

Local ethics committee approval was obtained before the study. Consent was obtained from all patients.

\section{Consent for publication}

We hereby give our consent for publication.

\section{Competing interests}

There are no competing interests.

\section{Author details}

'Orthopedic surgeon, Holy Spirit Hospital, Mahakali Caves Road, Andheri east, Mumbai, Maharashtra 400093, India. ${ }^{2}$ Orthopedic Surgeon, Criticare Superspeciality Hospital, Andheri East, Mumbai, Maharashtra, India. ${ }^{3}$ Interventional Pain \& Palliative Care Physician, Criticare Superspeciality Hospital, Andheri East, Mumbai, Maharashtra, India. ${ }^{4}$ Meril Life Sciences, Mumbai, India. ${ }^{5}$ Dr Vishwanath Karad MIT World Peace University, Pune, India. ${ }^{6}$ Criticare Superspeciality Hospital, Andheri East, Mumbai, India.

Received: 29 April 2020 Accepted: 21 January 2021

Published online: 29 March 2021

\section{References}

1. Fitzgerald JD, Orav EJ, Lee $\mathrm{TH}$, et al. Patient quality of life during the 12 months following joint replacement surgery. Arthritis\&Rheum. 2004;51:100-9.

2. Meding JB, Meding LK, Ritter MA, et al. Pain relief and functional improvement remain 20 years after knee arthroplasty. Clin Orthop Relat Res. 2012:470:144-9.

3. Said Al, Laura AS, Christopher JB, et al. Differences in expectations of outcome mediate African American/white patient differences in "willingness" to consider joint replacement. Arthritis\& Rheumatism. 2002;46(9):2429-35.

4. Ernest R. Vina, Yona K. Cloonan, Said a. Ibrahim et al race, gender and Total knee replacement consideration: the role of social support. Arthritis Care Res. 2013;65(7):1103-11.

5. Liang MH, Cullen KE, Larson MG, et al. Cost effectiveness of total joint arthroplasty in osteoarthritis. Arthritis Rheum. 1986;29:937-43.

6. Ahmad S, Ahmad I, Hammad S, et al. Factors related unwillingness of osteoarthritic patients for Total knee Arthroplasty. JPOA. 2018:30(1):17-20.

7. Zhao R, Carlson AM, Iffeld BM, et al. Patient factors in the decision to delay total knee arthroplasty. Presented at the International Society for Pharmaco economics and outcomes research 20th annual international meeting, may 16-20, 2015, in Philadelphia, Pennsylvania. https://icjr.net/articles/the-fearsthat-keep-candidates-for-tka-out-of-the-or.

8. Alattas SA, Smith T, et al. Greater pre-operative anxiety, pain and poorer function predict a worse outcome of a total knee arthroplasty. Knee surgery, sports traumatology \& Arthroscopy. 2017;25:3403-10.

9. Blackburn J, Qureshi A, Amirfeyz R, et al. Does preoperative anxiety and depression predict satisfaction after total knee replacement? Knee. 2012;19:522-4.

10. Hanusch $B C, O^{\prime}$ Connor DB, lons $P$, et al. Effects of psychological distress and perceptions of illness on recovery from total knee replacement. Bone Joint J. 2014;96-B:210-6.

11. Sandra H. Does preoperative psychologic distress influence pain, function, and quality of life after TKA? Clin Orthop Relat Res. 2014;472:2457-65.

12. Lopez-Olivo MA, Landon GC, Siff SJ, et al. Psychosocial determinants of outcomes in knee replacement. Ann Rheum Dis. 2011;70:1775-81.

\section{Publisher's Note}

Springer Nature remains neutral with regard to jurisdictional claims in published maps and institutional affiliations.
Ready to submit your research? Choose BMC and benefit from:

- fast, convenient online submission

- thorough peer review by experienced researchers in your field

- rapid publication on acceptance

- support for research data, including large and complex data types

- gold Open Access which fosters wider collaboration and increased citations

- maximum visibility for your research: over $100 \mathrm{M}$ website views per year

At $\mathrm{BMC}$, research is always in progress.

Learn more biomedcentral.com/submissions 